- Provides practical information on new legal requirements that will affect dental professionals.

- Gives broad guidance on how to comply with the new law.

- Identifies health risks for dental professionals.

- Presents a model for risk management.

\title{
The European vibration directive - how will it affect the dental profession?
}

\author{
N. J. Mansfield ${ }^{1}$
}

On 6 July 2005, the EU Physical Agents (Vibration) Directive (2002) came into force across all member states. This will mean that legally enforceable limits on hand-arm vibration exposures will be introduced and that risk management must be set in place at work. This article briefly describes the content of the Directive, how this will affect the dental profession and what measures will be required to ensure compliance.

\section{HAND-ARM VIBRATION SYNDROME}

Occupational exposure to vibrating tools can result in the occupational disease 'hand-arm vibration syndrome' (HAVS). ${ }^{1}$ The symptoms of HAVS are characterised by neurological and vascular components. ${ }^{2}$ Neurological components include reduced tactile sensitivity, finger numbness and tingling; the vascular components include painful finger blanching attacks that are triggered by cold and known as 'vibration white finger' (VWF). Susceptibility to and symptoms of HAVS vary markedly from person to person. Symptoms of VWF can often take many years to develop, but for susceptible workers, the disease can present after a few months of exposure. Initially, only a fingertip will be affected but if vibration exposure continues, the disease spreads proximally and to other digits. There is no effective treatment and most sufferers show no signs of recovery after cessation of vibration exposure. ${ }^{3}$ The severity of HAVS can be staged by using standardised scales such as the Stockholm

${ }^{1}$ Senior Lecturer in Ergonomics, Department of Human Sciences, Loughborough University, Loughborough, Leicestershire, LE11 3TU

Correspondence to: Dr Neil Mansfield

Email:n.j.mansfield@lboro.ac.uk

\section{Refereed Paper}

Accepted 14 April 05

doi: 10.1038/sj.bdj.4812902

๑ British Dental Journal 2005; 199: 575-577
Workshop Scale, ${ }^{4}$ Brammer's sensorineural scale $^{5}$ and Griffin's blanching scale. ${ }^{6}$ If a worker develops severe HAVS due to vibration at work and their employer is considered negligent, then compensation is likely to be payable. The largest personal injury scheme in British legal history involves coal miners who suffer from respiratory diseases and HAVS. Compensation for VWF alone reached $£ 1$ billion in 2004 for the 170,000 claimants, despite 80,000 still waiting for claims to be settled in full. ${ }^{7}$ Other high profile compensation cases have included workers in shipyards and users of breaker tools (eg pneumatic drills). Although there have been no similarly publicised cases of dentists seeking compensation for HAVS, any affected practitioner's reduction in dexterity could adversely affect their practical expertise.

\section{THE PHYSICAL AGENTS (VIBRATION) DIRECTIVE}

After several years of development and negotiation, the European Council of Ministers and European Parliament agreed the text of the Physical Agents (Vibration) Directive $^{8}$ in 2002. This came into force across the EU on 6 July 2005, and is implemented in the UK as the 'Control of Vibration at Work Regulations'.

At the heart of the Directive are two themes: minimisation of risk and criteria for action. For the Directive to apply, workers must be exposed to vibration that entails risks to their health and safety. If a risk exists then vibration exposure must be eliminated, if possible (Fig. 1). If it is not possible to eliminate the vibration, then risks must be reduced to a minimum and if a significant risk remains then health surveillance must be implemented. As part of the risk reduction, three courses of action must be taken.

The first course of action for those at risk from vibration is to assess and, if necessary, measure the vibration exposures. The total daily exposure to vibration is a function of both the magnitude and the duration of vibration. This is expressed in terms of the frequency-weighted eighthour energy-equivalent level and reported in $\mathrm{m} / \mathrm{s}^{2} \mathrm{~A}(8)$. For any vibration magnitude, an allowable exposure duration before exceeding any exposure criteria can be calculated. If a tool emits $10 \mathrm{~m} / \mathrm{s}^{2}$ r.m.s. while it is running, it would take two hours to reach a $5 \mathrm{~m} / \mathrm{s}^{2} \mathrm{~A}(8)$ threshold. If a tool emits $5 \mathrm{~m} / \mathrm{s}^{2}$ r.m.s. while it is running, it would take eight hours to reach a $5 \mathrm{~m} / \mathrm{s}^{2}$ $\mathrm{A}(8)$ threshold. When performing a risk assessment according to the Physical Agents (Vibration) Directive, the A(8) must be considered for each worker and compared to two criteria. The Exposure Action Value is defined as $2.5 \mathrm{~m} / \mathrm{s}^{2} \mathrm{~A}(8)$; the Exposure Limit Value is defined as $5 \mathrm{~m} / \mathrm{s}^{2}$ $A(8)$. If the $A(8)$ is below the Action Value, 


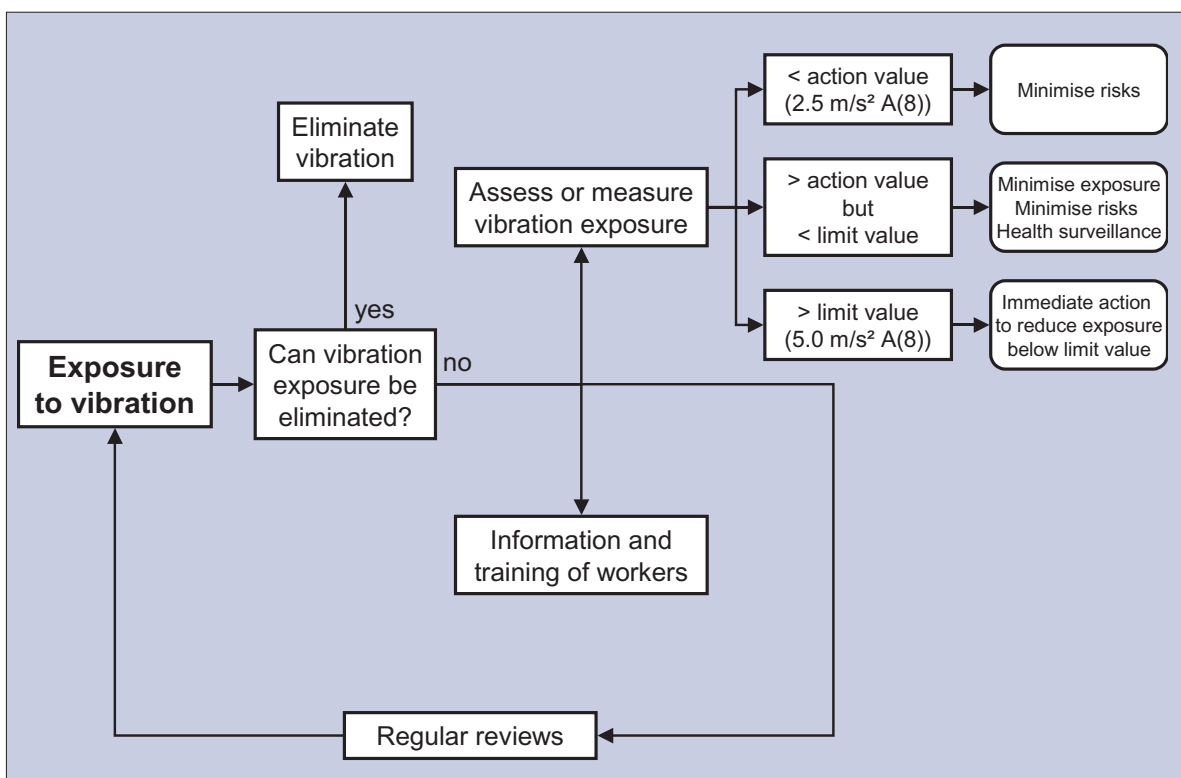

Fig. 1 Action required for reducing or eliminating exposure for those at risk according to the EU Physical Agents (Vibration) Directive (2002). (Adapted from Mansfield.) ${ }^{1}$

then the general requirement of risk minimisation applies. If the $\mathrm{A}(8)$ exceeds the Action Value, then exposures must be minimised, risks must be minimised and a programme of health surveillance must be implemented. The $\mathrm{A}(8)$ must not exceed the Limit Value. Minimisation of risk will involve controlling vibration exposures but also other confounding factors such as ensuring tools are ergonomically designed and that working postures are optimised.

The second required course of action is for employers to provide information and training for those at risk from vibration. The training will include how to identify and report vibration related disorders, principles for reducing vibration exposure and methods to reduce risk.

The third course of action required under the terms of the Directive is to regularly review workers' risks. Thus, if new methods of reducing vibration exposure or if improved methods of controlling risk are developed, these can benefit affected workers rapidly.

\section{APPLICABILITY OF THE PHYSICAL AGENTS (VIBRATION) DIRECTIVE TO THE DENTAL PROFESSION}

For the Physical Agents (Vibration) Directive to apply, a worker must be considered at risk of developing health disorders due to their vibration exposures. Although the prevalence of such disorders have been reported as relatively low among dentists, ${ }^{9}$ exposure to vibration from dental tools has been associated with early stages of hand-arm vibration syndrome for several years. ${ }^{10-12}$ More recently, Bylund et al. ${ }^{13}$ showed that, in Sweden, the highest incidence of vibration related injuries amongst women occurred for dental tech- nicians, dental hygienists and dentists. Relative risk of developing HAVS was greater for these dental professionals than for populations of female industrial workers such as for users of grinders and impact tools. However, unlike these unskilled workers, the majority of which were redeployed such that they were no longer exposed to hand-arm vibration, 83\% of dentists with HAVS still worked with the vibrating tools. Considering these studies, dental workers must be considered at risk of developing vibration related disorders. Therefore, a risk assessment should be conducted and vibration exposures compared to the Action and Limit Values specified in the Directive.

Measurement of hand-tool vibration is a multi-stage process. Accelerometers must be mounted to the tool to measure the acceleration (Fig. 2); signals from the accelerometers must be frequency weighted such that the human response to the vibration is modelled; ${ }^{14}$ the frequency weighted acceleration must then be aver-

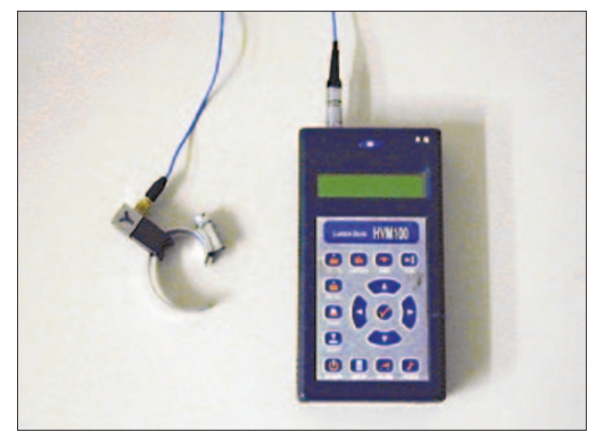

Fig. 2 Typical equipment used for measurement of occupational vibration exposures comprising a tri-axial accelerometer, mounting clip and human vibration meter. Such equipment is able to measure, frequency weight and provide data to enable calculation of $A(8)$ values. aged and combined with the daily exposure duration to generate the A(8) (Fig. 3). The vibration emission of dental tools is dominated by high frequency components above $1000 \mathrm{~Hz} ; ;^{15,16}$ the vibration from most industrial power tools is dominated by vibration at lower frequencies. As lower frequencies are considered the most important when assessing risks according to standardised methods, the frequency weighting means that measurement of the vibration of dental tools will generate minimal frequency-weighted values, despite generating high unweighted values. For example, Ishitake et al.'s measurements of dental tool vibration showed maximum values of $171 \mathrm{~m} / \mathrm{s}^{2}$ unweighted, but only $0.28 \mathrm{~m} / \mathrm{s}^{2}$ weighted. ${ }^{15}$ This contrasts with Burström et al.'s measurements of industrial grinders which showed similar unweighted vibration magnitudes of $170 \mathrm{~m} / \mathrm{s}^{2}$ but magnitudes of $5.2 \mathrm{~m} / \mathrm{s}^{2}$ when weighted ${ }^{17}$ (ie almost 20 times as much frequency weighted vibration as the dental tools). It would be impossible to reach the Physical Agents (Vibration) Directive's Exposure Action Value by using dental tools with weighted-vibration magnitudes as low as those reported in the literature. The applicability of the frequency weighting is therefore crucial in performing risk assessments of high speed tools and it remains a topic of some controversy. The US National Institute for Occupational Safety and Health (NIOSH) recommends that measurements are made both with and without the weighting ${ }^{18}$ and there is a growing body of evidence that casts doubt on the general applicability of the weighting (eg Griffin et al. $)^{19}$ Research aimed at improving the understanding of the general aetiology of HAVS continues, and such fundamental research might provide improved frequency weightings in the future. There is currently a lack of specific research focusing on HAVS in the dental profession.

\section{ACTION REQUIRED TO COMPLY WITH THE PHYSICAL AGENTS (VIBRATION) DIRECTIVE}

Dental professionals are at some risk of developing HAVS, therefore the Directive applies and the model shown in Figure 1 could be followed. It is not practical to eliminate vibration from the job, and therefore a risk assessment is required. Published data show that frequency weighted vibration emission of dental tools are very low and so the criteria in the Directive will not be exceeded for routine dental work. Considering the enigmatic nature of the human response to high-frequency tool vibration, measurements of vibration would not usually be considered necessary. This leaves four actions that 


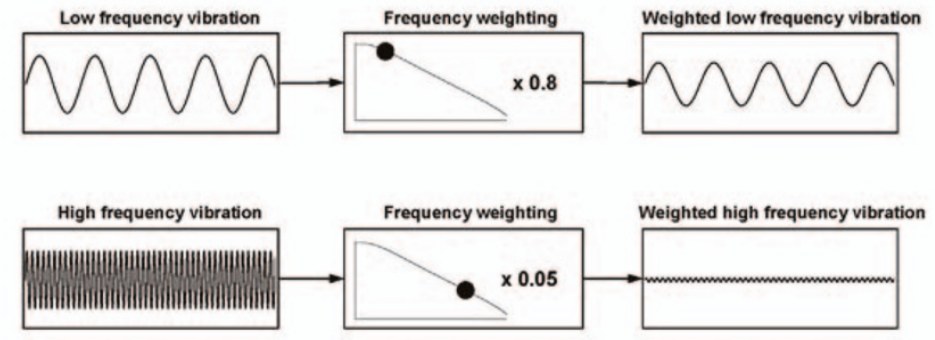

Fig. 3 Diagrammatic illustration of the effect of frequency weighting low frequency vibration, such as occurs for most industrial power tools and high frequency vibration, such as occurs for most dental tools. The weighting was developed from studies of hand-arm vibration perception and designed for application to heavy hand tools (such as chain saws and mining tools).

will be required: minimisation of risks, training, health surveillance and periodic reviews.

Minimisation of risks includes, but is not limited to, reducing vibration exposure. Risk minimisation in an industrial setting with unskilled workers usually includes redeployment to other jobs for those shown to be susceptible (ie showing early stages of HAVS) but this would not be considered acceptable for most dentists (although it might be appropriate for some technicians working in dental laboratories). Reduction of vibration magnitudes could be achieved by selecting handpieces and other equipment that can be shown to emit low magnitudes of vibration during normal use. Manufacturers have a responsibility to reduce risks to users as far as possible under the European Medical Devices Directive ${ }^{20}$ and must inform users of any residual risk. Therefore, in theory, manufacturers should be able to assist purchasers, although in practice this can prove difficult. Exposure times should also be minimised. This could be achieved by, for example, using a more efficient tool.

HAVS includes disorders, such as carpal tunnel syndrome (CTS), that can also occur when no vibration is present. Elevated risk of CTS and other musculoskeletal disorders occurs for those that are required to work in postures outside their 'neutral' range. Such deviated postures can occur during dental tasks if the workplace is poorly designed or improperly used. ${ }^{21}$ Similarly, poorly designed handpieces can accelerate fatigue and force poor postures that could result in wristarm disorders.
All employees at risk from vibration exposure should receive information and training. This should include training in how to minimise the risks from vibration, and how to recognise and report any signs of injury. In a large organisation (eg a hospital) reporting of injury could occur through a mediator (such as a trade union). Self-employed individuals also have a duty to comply and therefore might need training by an external body. Health records should be kept, as for all risks. ${ }^{22}$ If any individual is identified as possibly suffering from HAVS, this would need confirmation by a doctor. This person would then need a more in-depth risk management strategy and closer health surveillance to ensure that symptoms do not deteriorate.

\section{Summary}

Exposure to hand-arm vibration can result in a condition known as Hand-Arm Vibration Syndrome (HAVS) that includes vascular and neurological components. It is most often seen amongst those operating industrial power tools, but there is evidence that dental workers are also at risk. Under the European Physical Agents (Vibration) Directive which was implemented in July 2005, all those at risk of vibration related disorders will need a risk assessment. Although the magnitudes of vibration will not approach the Exposure Action Value or Exposure Limit Value as set out in the Directive, risks will still need to be minimised. This could be achieved by reducing exposure times, health surveillance, use of improved handpieces and other equipment, and by improving the overall ergonomics of the workplace.
1 Mansfield N J. Human response to vibration. USA: CRC Press 2005.

2. Burke F J T, Jaques S A. Vibration white finger. Br Dent J 1993; 174: 191.

3. Futatsuka M, Fukuda Y. A follow up study on the consequences of VWF patients in the workers using chain saws. In Lundström R, Lindmark A (Eds). Proceedings of 8 th International Conference on Hand-Arm Vibration, 9-12 June 1998. Umeå, Sweden.

4. Gemne G, Pyykko I, Taylor W, Pelmear P. The Stockholm Workshop scale for the classification of cold-induced Raynaud's phenomenon in the hand-arm vibration syndrome (revision of the Taylor-Pelmear scale). Scand JWork Environ Health 1987: 13: 275-278.

5. Brammer A J, Taylor W and Lundborg G. Sensorineura stages of the hand-arm vibration syndrome. Scand J Work Environ Health 1987; 13: 279-283.

6. Griffin M J. Handbook of human vibration. London: Academic Press, 1990

7. Department of Trade and Industry. Compensation for miners: Looking ahead. Coal Health Claims 2004; 9.

8. European Commission. Directive 2002/44/EC of the European Parliament and of the Council of 25 June 2002 on the minimum health and safety

requirements regarding the exposure of workers to the risks arising from physical agents (vibration). Official Journal of the European Communities; L177.

9. Jaques S A, Burke FJ T. Vibration white finger. Br Dent J 1994; 177: 279

10. Lundström $R$, Lindmark $A$. Effects of local vibration on tactile perception in the hands of dentists. J Low Freq Noise Vibration 1982: 1: 1-11.

11. Åkesson I, Lundborg G, Horstmann V and Skerfving S. Neuropathy in female dental personnel exposed to high frequency vibrations, Occup Environ Med. 1995, 52: 116-123.

12. Åkesson I, Johnsson B, Rylander L, Moritz U, Skerfving $S$. Musculoskeletal disorders among female dental personnel - clinical examination and a 5-year follow-up study of symptoms. Int Arch Occup Environ Health, 1999, 72: 395-403.

13. Bylund $S \mathrm{H}$, Burström L, Knutsson A. A descriptive study of women injured by hand-arm vibration. Ann Occup Hyg 2002, 46: 299-307.

14. International Organization for Standardization. Mechanical vibration: measurement and evaluation of human exposure to hand transmitted vibration Part 1: general guidelines. ISO 5349-1. Geneva: International Organization for Standardization, 2001

15. Ishitake T, Ando M, Maeda S, Takahashi Y, Yonekawa Y. The measurement of vibration level in dental vibratory equipment and its effect on peripheral function in healthy volunteers. Proceedings of the 9th Japan Group Meeting on Human Response to Vibration. 25-27 July 2001. Mito, Japan.

16. Cherniak M. Vibration and dental equipment. In Murphy D C. Ergonomics and the dental care worker. Washington: American Public Health Association, 1998

17. Burström L, Lundström R, Hagberg M, Nilsson T. Comparison of different measures for hand-arm vibration exposure. Safety Science 1998; 28: 3-14.

18. National Institute of Occupational Safety and Health (NIOSH). Criteria for a recommended standard for occupational exposure to hand-arm vibration. Cincinnati: NIOSH publication 89-106, 1989.

19. Griffin M J, Bovenzi M, Nelson C M. Dose-response patterns for vibration induced white finger. Occup \& Environ Med 2003, 60: 16-26.

20. European Commission. Directive 1993/44/EC of the European Parliament and of the Council of 14 June 1993 concerning medical devices. Official Journal of the European Communities. L169.

21. Murphy D C. Ergonomics and the dental care worker. Washington: American Public Health Association.

22. Her Majesty's Stationary Office. The Management of Health and Safety at Work Regulations. 1999. 